\title{
Novas formas de organização da produção e do trabalho: formação de redes de produção na empresa Moto Honda da Amazônia?
}

Eudes Lopes Melo - Mestrando do Programa de Pós-Graduação em Sociologia da Universidade Federal do Amazonas (UFAM).

Izabel Valle - Doutora em Sociologia pelo Instituto de Filosofia e Ciências Sociais da Universidade Federal do Rio de Janeiro (UFRJ). Professora do Departamento de Ciências Sociais do Instituto de Ciências e Letras (ICHL) da UFAM.

Charles Maciel Falcão - Professor de Sociologia do Instituto de Saúde e Biotecnologia, Unidade Acadêmica de Coari, da UFAM. Mestrando do Programa de Pós-Graduação em Sociologia da UFAM.

\section{Resumo}

A formação de cadeias produtivas no Pólo Industrial de Manaus do setor duas rodas é indicativa das novas estratégias locais de produção. Oimperativo da competitividade é motivo para que a empresa Moto Honda da Amazônia cerque-se de fornecedores locais a fim de facilitar sua produção, reduzir custos e ampliar seu faturamento. Este faturamento tem apresentado crescimento nos últimos dez anos que ocorre paralelamente ao aumento progressivo da compra de insumos regionais e ao aumento da força de trabalho. Nossa pesquisa revelou a necessidade de examinar mais profundamente como as novas estratégias produtivas, na fase atual da indústria, têm atribuído um novo significado à produtividade e levado as empresas a ocuparem um lugar de liderança no mercado, em espaços descentralizados da produção industrial.

\section{Palavras-Chave}

Organização produtiva; trabalho; estratégias empresariais; Moto Honda; Amazônia

\begin{abstract}
The formation of productive chains in the Industrial Pole of Manaus in the twowheels sector is an indicative of the new local production strategies. The imperative of the competitiveness is a reason for the company Moto Honda of Amazonia to get surrounded by local suppliers in order to facilitate its production, to reduce costs and to amplify its profits. This profit has been increasing in the last ten years, which occurs parallel to the progressive increase of purchase of regional production input and to the increase of the work force. We have started in the necessity of understanding the new productive tendencies. Our research revealed the necessity of examining, in a deeper way, how the new productive strategies, in the current phase of the industry, have scribed a new meaning to the productivity and taken the companies to occupy a place of leadership in the market, in decentralized spaces of the industrial production.
\end{abstract}

\section{Keywords}

Productive organization; work; business strategies; Moto Honda; Amazonia 


\section{INTRODUÇÃO}

As novas estratégias de produção têm-se afirmado em diversos espaços, territórios, ilhas, arquipélagos (IANNI, 1999). A empresa matriz da produção não é mais uma realidade única. As facilidades oferecidas pela tecnologia dos transportes e das comunicações possibilitaram a instalação das corporações nos diversos pontos do planeta (VALLE, 2007).

A difusão territorial dos processos produtivos consiste na descentralização da produção, fora da fábrica, na terceirização e em um processo ainda "mais complexo, que implica uma reversão da própria relação que liga a fábrica a seu meio, entendido como território das relações sociais de cooperação" (COCCO, 2001, p. 97-98).

O fenômeno do deslocamento das organizações é assim explicado por Ramalho (2006, p. 13):

A facilidade com que as fábricas 'enxutas' conseguem se deslocar de um espaço geográfico para outro teria significado, por um lado, o aumento do poder discricionário das empresas, sempre em busca de lugares com mão-de-obra barata e grandes incentivos fiscais (como acontece com os países tardiamente industrializados); por outro lado, teria feito crescer a importância econômica e política dos locais onde estão instaladas as empresas reestruturadas, a partir do momento em que esses locais passaram a fazer parte de um circuito global.

A formação de cadeias produtivas no Pólo Industrial de Manaus (PIM), no setor de duas rodas é indicativa das novas estratégias locais de produção. $\mathrm{O}$ imperativo da competitividade é motivo para que a empresa Moto Honda da Amazônia (MHA) cerque-se de fornecedores locais a fim de facilitar sua produção, reduzir custos e ampliar seu faturamento. $\mathrm{O}$ faturamento da MHA tem apresentado crescimento nestes últimos dez anos que ocorre paralelamente ao aumento progressivo da compra de insumos regionais e ao aumento da força de trabalho.

\section{GLOBALIZAÇÃO: A EMPRESA CAPITALISTA E OS DESLOCAMENTOS DAS UNIDADES PRODUTIVAS}

Partimos da necessidade de compreender as novas tendências produtivas. Com efeito, novas estratégias de produção industrial estão sendo adotadas no processo de deslocamento produtivo para novos territórios. Nessa perspectiva, entendemos que a Zona Franca de Manaus (ZFM) e seus desdobramentos correspondem diretamente ao processo de internacionalização da economia. Constatamos, ainda, a expansão da produção, da oferta de trabalho, da aquisição 
de insumos, do faturamento no setor de duas rodas do Polo Industrial de Manaus (PIM), em particular da Moto Honda da Amazônia. Essa fábrica de motocicletas lidera, em todos os aspectos, a produção industrial no subsetor do Polo de Duas Rodas, o que indica a mudança nas estratégias de produção no mercado global e local. De fato, essas estratégias significam uma importante transformação na relação entre as empresas fornecedoras desse polo e a MHA e demais fábricas de duas rodas.

Para compreender esses movimentos conjunturais, relativos ao deslocamento das indústrias, inseridas nos espaços locais, é necessário situá-los em relação à ideia do global e do local. É preciso abordar problemas e questões relativas à globalização, por meio de questionamentos e da investigação desde as suas raízes até as suas consequências sociais (BAUMAN, 1999).

Nosso estudo nasce da necessidade de examinar mais profundamente como as novas estratégias produtivas têm, na fase atual da indústria, atribuído um novo significado ao espírito da produtividade, para driblar a competitividade e levar as empresas a ocupar o lugar de liderança no mercado, em espaços descentralizados da produção industrial. Nesse caso, o tempo e o espaço devem ser encarados como mundos, cuja mudança afeta os mais profundos valores e paradigmas de grupos, classes, tribos, etc.. O global pode estar ou ser local, ao mesmo tempo que o local pode estar ou ser global. Assim, ser global e ser local têm significados antagônicos: de um lado, o global tem o signo do domínio e ser local é viver o desconforto da dependência do ser global em todos os sentidos.

Nesses termos, a mobilidade é uma válvula de escape que os novos investidores adotam hoje como estratégia: gozam da liberdade de custos, no frio cálculo, do poder de investir sem preocupar-se com as obrigações sociais. Esse movimento inaugura uma desconexão entre gozar de liberdade para utilizar-se da exploração e desprezar as consequências desse ato (BAUMAN, 1999). Essa mobilidade tem uma implicação direta na empresa capitalista. Sua dispersão geográfica exige soluções flexíveis. O que leva a dizer que o capitalismo tende a ser mais organizado, além de aumentar sua capacidade de se reproduzir, pelo fato de essa mobilidade permitir maior flexibilidade no mercado de trabalho e no conjunto da economia (HARVEY, 1992).

No plano local, tudo isso pode engendrar outras possibilidades: "A questão do desemprego, da pobreza, das desigualdades regionais, das desigualdades raciais e de classe subsume-se na globalização da questão social, que acentua as crises nacionais" (SILVA, 2000, p. 268). É possível ver aqui a combinação de, pelo menos, três totalidades: regional, nacional, global. 
O deslocamento das indústrias ocorre no contexto da globalização. Daí a quase inexistente relação de oposição entre "dentro" e "fora" em coisas e na humanidade. A velocidade da comunicação e dos transportes tem diminuído gradualmente a disjunção entre longe e perto (BAUMAN, 1999). Esse fenômeno está diretamente ligado à implantação da rede de computadores e estabelece, teórica e praticamente, o fim das distâncias. Trata-se de uma mudança do caráter do espaço, que se desprende da subordinação natural do corpo humano, ao dificultar a solidariedade, os conflitos interpessoais e demais resoluções físicas mediadas pela proximidade (BAUMAN, 1999).

A rede mundial de informática reordenou também o espaço, e isso explica o fato de o espaço cibernético assumir o lugar do espaço planejado, "territorialurbanístico-arquitetônico", embora este último não seja comum a todas as pessoas. Com efeito, nem todos os espaços podem ser frequentados por todos. Admite-se, ainda, que seja possível separar pessoas por obstáculos físicos e distâncias temporais, sobretudo porque se trata de um processo ainda transitório (BAUMAN, 1999). O problema exposto aqui diz respeito à nova realidade contemporânea, que está experimentando o liame entre a condição humana e a sua perda. Os padrões bipolares de mundo expõem, de um lado, uma realidade que oferece dignidade e, de outro, uma realidade que oferece a humilhação; de um lado, um mundo revelado pelos que ostentam riqueza, de outro, um grupo que experimenta social e materialmente a miséria conforme Bauman, (1999).

\section{NOVAS TENDÊNCIAS NA ORGANIZAÇÃO DA PRODUÇÃO}

As três últimas décadas foram marcadas pela desestruturação do ciclo de produção e da forma de reprodução do capital. Em decorrência disso, a crise do modelo fordista levou a um deslocamento de vários setores das forças de trabalho dos centros metropolitanos de produção para espaços territoriais, nos quais passaram a desempenhar microatividades industriais (COCCO, 2001).

As análises que explicam a crise do capital do final da década de 60 e início da década de 70 põem em relevo o declínio da produtividade e dos lucros das empresas após 1966. Para os analistas, a crise afetou diretamente a arrecadação pública dos Estados Unidos, cuja moeda, após a aceleração da inflação, assumiu o status de moeda-reserva internacional (ANTUNES, 1999; HARVEY, 1992). Somase a isso a crise em proporções internacionais do capital imobiliário e a paralisia das instituições financeiras. Encontram-se ainda as consequências da elevação do 
preço do petróleo e o embargo do fornecimento de petróleo ao Ocidente, como observado no contexto da guerra entre árabes e israelenses, em 1973.

Os efeitos disso foram formas diversas de economizar energia. A deflação entre 1973 e 1975 gerou uma séria crise "fiscal e de legitimação". A falência técnica de Nova Iorque revelou o quanto o problema era grave. Simultaneamente a isso, a capacidade de criar excedente levou as corporações a lançar-se numa desenfreada competição. Esses fatores explicam a racionalização, a reestruturação e a intensificação do controle do trabalho:

A mudança tecnológica, a automação, a busca de novas linhas de produto e nichos de mercado, a dispersão geográfica para zonas de controle do trabalho mais fácil, as fusões e medidas para acelerar o tempo de giro do capital passaram ao primeiro plano das estratégias corporativas de sobrevivência em condições gerais de deflação (HARVEY, 1992, p. 1367-140).

Um dos efeitos da recomposição da lógica geral do capital é a falência de parques industriais inteiros de determinadas regiões que não suportam ficar de pé, por causa do peso da concorrência desigual das grandes corporações e da força da empresa transnacional. No entanto, não menos afetado e destruído é o contingente enorme de trabalho e de forças produtivas, de populações que vivem de salário, em precárias condições de trabalho ou nas redes da informalidade (ANTUNES, 1999). É o "resto", isto é, são aqueles indivíduos que nem sequer puderam escolher, opinar sobre a sua condição. Trata-se de uma situação de total desvantagem, por estarem situados no espaço local conectado ao global.

Essa reorganização estratégica do capital caracteriza-se, sobretudo, pela novidade dos setores de produção, de serviços financeiros, pelas elevadas taxas nos componentes das relações de produção, da tecnologia e do comércio, pela ampliação do movimento do setor de serviços, por meio do desenvolvimento desigual entre setores e até mesmo entre regiões, pela capacidade de criar novas indústrias em lugares antes inteiramente subdesenvolvidos. É o caso de algumas regiões que ficaram conhecidas como a "terceira Itália", Flandres, assinalado por Castells (2006).

Outro aspecto dessa reorganização é o alto índice de desemprego estrutural, com veloz capacidade de eliminação de habilidades e baixos salários, além da subcontratação, do recuo e do controle do poder de articulação do movimento sindical (CASTELLS, 2006). 
A acumulação flexível também reduziu o tempo de utilidade do produto em setores como o têxtil e o de vestuário ${ }^{1}$.

\section{FORMAÇÃO DE REDES DE PRODUÇÃO NO POLO DE DUAS RODAS (PDR) E NA MOTO HONDA DA AMAZÔNIA (HDA)}

Entende-se por redes de produção um tipo de organização em redes, como a rede produtiva Benetton. Trata-se de uma forma intermediária de arranjo entre a desintegração vertical por meio dos sistemas de subcontratação de uma grande empresa e as redes horizontais das pequenas empresas. É uma rede horizontal, mas baseada em um conjunto de relações periféricas ou centrais, tanto no lado da oferta como no lado da demanda do processo (CASTELLS, 2006).

No plano das organizações das empresas, podemos lembrar também a experiência da implantação de redes produtivas nos Estados Unidos, usada como estratégia para aumentar o controle financeiro da empresa. Pode-se constatar a expansão e a transparência no interior dos negócios de cada organização. Verificase, ainda, que a transformação organizacional ocorreu independentemente da transformação tecnológica.

Há dois tipos de organização: organizações nas quais a reprodução do sistema de meios transforma-se em objetivo organizacional fundamental e organizações nas quais os objetivos e as mudanças de objetivos modelam e remodelam de forma infinita a estrutura dos meios. Com base nessa diferenciação conceitual, Castells (2006) propõe um conceito de empresa-rede: uma forma específica de empresa cujo sistema de meios é constituído pela interseção de segmentos de sistemas autônomos de objetivos. É nesses termos que iria ocorrer a materialização da empresa-rede em uma forma definida de cultura econômica informacional global, num movimento de atividades econômicas virtuais pelo processamento de conhecimento (CASTELLS, 2006).

A internacionalização generalizada do capital é um fenômeno que se dá de modo combinado com a mundialização do processo produtivo. As sedes das grandes organizações industriais não se concentram mais somente nos chamados países centrais.

\footnotetext{
1 "A acumulação flexível foi acompanhada na ponta do consumo, portanto, por uma atenção muito maior às modas fugazes e pela mobilização de todos os artifícios de indução de necessidades e de transformação cultural que isso implica. A estética relativamente estável do modernismo fordista cedeu lugar a todo o fermento, instabilidade e qualidades fugidias de uma estética pós-moderna que celebra a diferença, a efemeridade, o espetáculo, a moda e a mercadificação de formas culturais" (HARVEY, 2006, p. 148).
} 
As unidades e organizações produtivas, envolvendo inovações tecnológicas, zonas de influência, adequações culturais e outras exigências da produção, distribuição, troca e consumo das mercadorias que atendem as necessidades reais ou imaginárias, passam a desenvolver-se nos mais diversos países, distribuindo-se por continentes, ilhas e arquipélagos. Assim como se multiplicam as zonas francas, multiplicam-se e dispersam-se as unidades e organizações produtivas (IANNI, 1999, p. 62-63).

Nessa trilha, há três condições para a criação de centros industriais de transformação. A primeira está ligada à grande quantidade de trabalhadores com disponibilidade e ao baixo custo na troca de trabalho por salário. A segunda é a possibilidade de uma mão de obra semiqualificada poder participar da produção, em decorrência da fragmentação do processo produtivo. A terceira tem relação com as facilidades oferecidas pelas comunicações e transportes, dadas as condições do desenvolvimento tecnológico (VALLE, 2007).

Na Amazônia, a inserção do capital internacional dá-se no final da década de 60, com a instalação da Zona Franca em Manaus. Logo, a Zona Franca de Manaus é parte extensiva do processo de globalização. Sua implantação ocorre em um quadro favorável, no qual todas as condições de ordem jurídica e política foram oferecidas às organizações industriais internacionais. Desde o início, as indústrias aplicaram à força de trabalho um baixo padrão de remuneração. Além de serem favorecidas pela isenção de impostos, as indústrias foram beneficiadas pela ditadura militar, porque esse ambiente político representava a segurança de uma mão de obra disciplinada:

[...] a cooperação entre o militarismo, a economia mundial e o nacionalismo - faz parte de um momento definido da ordem internacional. Essa concatenação de interesses determina a escolha do lugar de experimentação de uma das primeiras zonas francas do mundo; determina também os modos de compatibilizar a "ordem nacional" com a "ordem mundial"; e, finalmente, determina a contrapartida que os países "periféricos", "dependentes", podem obter por constituírem-se em área de expansão da acumulação capitalista. O que importa é reforçar que a concepção e a decisão de implantação da Zona Franca de Manaus são oriundas de processos e relações mais amplas que efetivam um movimento de descentralização da produção capitalista fora das suas zonas originárias (SERÁFICO; SERÁFICO, 2005, p. 102).

Segundo a análise de José Seráfico e Marcelo Seráfico (2005), a criação da Zona Franca de Manaus deveu-se a circunstâncias de ordem superestrutural, principalmente à ditadura militar. Politicamente, havia um contexto propício para a germinação de uma mão de obra comportada, adequada às metas do capital das multinacionais. Mas, para garantir a instalação da Zona Franca de Manaus, 
foram tomadas algumas iniciativas, cujo objetivo era redimensionar o quadro de estagnação econômica, no qual as condições de emprego eram negativas.

Dentre as medidas adotadas, destacam-se: o estabelecimento de "uma área mínima de 10 mil km²" - o que incluía Manaus e seu entorno -, a isenção fiscal de importação para as matérias-primas e os produtos destinados à Zona Franca de Manaus, a isenção de impostos de exportação para os produtos brasileiros destinados ao exterior, a fim de assegurar à produção nacional condições de concorrência com a importação estrangeira.

O desenvolvimento da ZFM é emblemático de uma indústria que, embora não se tenha configurado como uma força autônoma, recebe uma forte pressão externa, pela sua própria natureza. O capital da ZFM é fundamentalmente externo. Além disso, todo o aparato tecnológico, gerencial, administrativo e econômico é externo. O único elemento local de peso na formação do capital orgânico da indústria da ZFM é a força de trabalho.

Nesse sentido, o trabalho local é fortemente determinado pelos interesses dos de dentro, dos globais, dos proprietários que operam virtualmente o capital e têm, ao mesmo tempo, acesso ao universo do consumo, do turismo, do seguro de vida, do transporte aéreo para seus escritórios. Essa "compatibilidade" depende dos resultados que a mão de obra constituída pelos de fora oferece, principalmente no enquadramento da sua atividade no sistema de trabalho flexível. Portanto, apesar do oferecimento de isenção de cerca de 18 impostos às multinacionais instaladas na ZFM, a força de trabalho é uma determinante na interação entre o local e o global, na operação da indústria.

O Decreto-Lei n. ${ }^{\circ}$ 288, de 28 de fevereiro de 1967, que regula a Zona Franca de Manaus, sofreu, desde a sua aprovação, várias mudanças para atender demandas diversas dos setores da indústria do Polo Industrial de Manaus. Essas alterações têm por finalidade regulamentar as ações empresariais e oferecer mais estabilidade à atividade industrial no Amazonas. Essas ações encontram-se, assim, fundamentadas em uma série de decretos. Podemos citar alguns que são exemplares pela sua importância, como o Decreto-Lei n. ${ }^{\circ} 356 / 68$, que amplia os benefícios ficais para a Amazônia Ocidental, e o Decreto-Lei n. ${ }^{\circ}$ 1435/75, que trata da exigibilidade do Imposto Sobre Importação, na saída da matéria-prima para qualquer ponto do país. Outras alterações importantes foram introduzidas pelo Decreto-Lei n. ${ }^{\circ}$ 92560, de 16 de abril de 1986, que prorroga por mais 10 (dez) anos o prazo de vigência da lei de isenções fiscais concedidas à Zona Franca de Manaus. 


\begin{tabular}{|l|r|r|r|r|}
\hline \multicolumn{5}{|c|}{ Setor Industrial } \\
\hline \multirow{2}{*}{ Anos } & \multicolumn{5}{|c|}{ Aquisição de Insumos (em US\$) } \\
\cline { 2 - 5 } & \multicolumn{1}{|c|}{ Regional } & Nacional & \multicolumn{1}{c|}{ Exterior } & \multicolumn{1}{c|}{ Total } \\
\hline 1990 & 114.320 .007 & 119.926 .235 & 64.844 .747 & 377.090 .989 \\
\hline 1991 & 66.333 .726 & 94.187 .424 & 39.845 .729 & 200.366 .879 \\
\hline 1992 & 62.379 .919 & 85.630 .938 & 43.797 .828 & 191.808 .685 \\
\hline 1993 & 48.716 .886 & 74.015 .059 & 72.949 .332 & 195.681 .277 \\
\hline 1994 & 188.680 .341 & 228.158 .724 & 128.176 .479 & 545.015 .544 \\
\hline 1995 & 227.422 .601 & 210.313 .632 & 252.755 .377 & 690.491 .610 \\
\hline 1996 & 341.131 .907 & 240.337 .391 & 215.846 .909 & 797.316 .207 \\
\hline 1997 & 492.255 .418 & 334.440 .129 & 336.701 .807 & 1.163 .397 .354 \\
\hline 1998 & 467.804 .358 & 307.768 .778 & 254.165 .219 & 1.029 .738 .355 \\
\hline 1999 & 321.764 .262 & 204.165 .115 & 193.202 .000 & 719.131 .377 \\
\hline 2000 & 411.696 .677 & 272.821 .913 & 309.386 .579 & 993.905 .169 \\
\hline 2001 & 434.088 .156 & 283.167 .958 & 272.682 .099 & 989.938 .213 \\
\hline 2002 & 472.337 .243 & 281.133 .373 & 239.126 .458 & 992.597 .074 \\
\hline 2003 & 594.069 .780 & 346.816 .141 & 284.132 .589 & 1.225 .018 .510 \\
\hline 2004 & 641.486 .280 & 416.345 .955 & 260.671 .275 & 1.318 .503 .510 \\
\hline 2005 & 858.420 .020 & 588.350 .424 & 348.626 .842 & 1.795 .397 .286 \\
\hline 2006 & 1.172 .949 .290 & 858.708 .195 & 537.933 .363 & 2.569 .590 .847 \\
\hline
\end{tabular}

Quadro 1: Aquisição de insumos do subsetor duas rodas (de 1990 a 2006).

FONTE: SAP/CGPRO/COISE 2 .

O período que estamos avaliando, indicado no quadro acima, é revelador de uma tendência de expansão substancial na aquisição de insumos nacionais em relação às aquisições de insumos do exterior no subsetor de duas rodas. Percebe-se ainda que, no período de 1996 a 2006, ocorreu proporcionalmente uma significativa elevação da aquisição de insumos regionais por esse subsetor em relação às aquisições de insumos nacionais e do exterior.

É possível indicar uma tendência de aumento progressivo na produção do subsetor de duas rodas, não somente pela decisão de adquirir de fornecedores locais, mas também pelas vantagens auferidas na natureza dos custos de produção. Dizemos isso com base no crescimento das aquisições regionais: quando comparadas às aquisições nacionais e do exterior, evidenciam uma ampliação das empresas fornecedoras, que têm acompanhado as empresas desse subsetor, desenvolvendo-se num movimento sincronizado com elas.

Esse dado deve ser considerado um sinal de uma mudança políticojurídico-administrativa no âmbito do "novo regime da Política Industrial e de Comércio Exterior, desencadeada a partir do início dos anos 90 do século passado e estruturada no conceito de competitividade" (BOTELHO, 2006, p. 35). 
Na esfera regulatória, a promulgação da Lei n. ${ }^{\circ}$ 8.387, de 30 de dezembro de 1991, que institui o índice mínimo de nacionalização para as etapas básicas da produção, redimensiona o conjunto da produção no Polo Industrial de Manaus. O primeiro efeito dessa mudança pode ser sentido a partir da instalação de máquinas modernas nas plantas das fábricas do conjunto do PIM. Isso teve uma implicação direta na planta básica dessas fábricas.

A MHA é atingida por essa mudança o que fica mais claro ao olharmos os valores da utilização da capacidade instalada (UCI) ${ }^{3}$. Em dezembro de 1991, a UCI da MHA representava 53 apenas; em dezembro de 1992, a UCI foi reduzida a 31; em dezembro de 1993, a UCI indicava 56; em 1994, 1995, 1996, 1997 e 1998, a UCI não somente aumentou como se estabilizou em cem por cento, com exceção dos meses de janeiro de 1997, em que a UCI ficou em 96, e de agosto e dezembro de 1998, em que a UCI caiu para 81 e 75, respectivamente. Após a baixa de 1999 - UCI de 85 em dezembro -, nos anos subsequentes - de 2000 a 2006 -, a UCI fechou todos os meses em cem por cento da sua capacidade produtiva (SINDI/FIEAM/CNI, 2008) ${ }^{4}$.

A atividade da indústria do Polo de Duas Rodas sofreu uma surpreendente alteração na rotina da sua produção. Como mostra o quadro abaixo, a partir de 1999, a produção desse subsetor atingiu 505.352 unidades produzidas. Em 2000, foram produzidas 641.607 motocicletas. Em 2001, esse setor atingiu 778.334 unidades; em 2002, a produção foi elevada para 865.602 unidades; em 2003, saltou para 954.809. Logo, a dinâmica da produção é sempre crescente (SUFRAMA: COISE/SAP/CGPRO, 2008) ${ }^{5}$.

\begin{tabular}{|r|r|}
\hline \multicolumn{2}{|c|}{ Setor industrial } \\
\hline Anos & \multicolumn{1}{|c|}{ Produção de motocicletas } \\
\hline 1990 & 143.533 \\
\hline 1991 & 123.159 \\
\hline 1992 & 82.518 \\
\hline 1993 & 83.361 \\
\hline 1994 & 145.346 \\
\hline 1995 & 243.133 \\
\hline 1996 & 295.957 \\
\hline
\end{tabular}

3 Corresponde a capacidade de produção instalada e operada. Os valores podem refletir se a fábrica opera com todas máquinas instaladas ou somente parte com da sua capacidade.

4 FEDERAÇÃO DAS INDÚSTRIAS DO ESTADO DO AMAZONAS. Desempenho - Pólo Industrial de Manaus, 2008.

5 SUPERINTENDÊNCIA DA ZONA FRANCA DE MANAUS. Indicadores de desempenho do Pólo Industrial de Manaus: história do PIM em tabelas e tráficos, 1988 a 2006, p. 67. 


\begin{tabular}{|r|r|}
\hline 1997 & 430.398 \\
\hline 1998 & 482.113 \\
\hline 1999 & 505.352 \\
\hline 2000 & 641.607 \\
\hline 2001 & 778.334 \\
\hline 2002 & 865.602 \\
\hline 2003 & 954.823 \\
\hline 2004 & 1.052 .941 \\
\hline 2005 & 1.253 .149 \\
\hline 2006 & 1.516 .444 \\
\hline
\end{tabular}

Quadro 2: Produção de motocicletas do subsetor duas rodas (de 1990 a 2006).

FONTE: SAP/CGPRO/COISE 6 .

A produção de motocicletas no subsetor de duas rodas apresenta uma evolução crescente no período de 1992 a 2006, conforme o quadro acima. Embora tenha variado numericamente entre 1990 e 1991, a produção desse período deu um salto significativo em relação aos resultados da produção dos anos anteriores.

Esse crescimento pode ser em parte explicado pela intensificação das relações entre as empresas do subsetor de duas rodas e seus fornecedores. Em entrevista a Paulo Ricardo Braga, do site Automotive Business, Moacyr Paes, diretor executivo da Associação Brasileira dos Fabricantes de Motocicletas, Ciclomotores, Motonetas, Bicicletas e Similares (ABRACICLO), declara: "Para minimizar as dificuldades na absorção dos preços dos insumos, fabricantes e fornecedores de componentes trabalham próximos para equacionar custos e margens, buscando oportunidades de crescimento conjunto" (HONDA..., 2004). A expansão da produção é realmente considerável, se compararmos a produção de 1992 aos resultados de 2006.

\begin{tabular}{|r|r|}
\hline \multicolumn{2}{|c|}{ Setor industrial } \\
\hline Anos & \multicolumn{1}{|c|}{ Faturamento (valores em US\$1,00) } \\
\hline 1990 & \\
\hline 1991 & 740.965 .734 \\
\hline 1992 & 452.751 .721 \\
\hline 1993 & 328.632 .938 \\
\hline 1994 & 401.044 .669 \\
\hline
\end{tabular}

6 Idem. 


\begin{tabular}{|l|r|}
\hline 1995 & 1.014 .187 .134 \\
\hline 1996 & 1.245 .705 .837 \\
\hline 1997 & 1.674 .820 .555 \\
\hline 1998 & 1.662 .009 .229 \\
\hline 1999 & 1.070 .979 .051 \\
\hline 2000 & 1.579 .445 .964 \\
\hline 2001 & 1.554 .779 .557 \\
\hline 2002 & 1.325 .839 .716 \\
\hline 2003 & 1.848 .842 .202 \\
\hline 2004 & 2.347 .461 .760 \\
\hline 2005 & 3.154 .706 .723 \\
\hline 2006 & 4.192 .007 .520 \\
\hline
\end{tabular}

Quadro 3: Produção de motocicletas do subsetor duas rodas (de 1990 a 2006).

FONTE: SAP/CGPRO/COISE8 ${ }^{7}$.

O faturamento do subsetor de duas rodas sofre altas e quedas. É importante observar que os valores dos primeiros anos da década de 90 são extremamente modestos. Esses baixos valores refletem o processo de adaptação da abertura alfandegária do governo federal em 1991 (ALVES, 2005). No entanto, vale ressaltar que, de 2003 a 2006, o faturamento apresentou cifras crescentes.

\begin{tabular}{|r|r|}
\hline \multicolumn{2}{|c|}{ Setor industrial } \\
\hline Anos & \multicolumn{1}{|c|}{ Faturamento } \\
\hline 1990 & \\
\hline 1991 & 4.056 \\
\hline 1992 & 2.979 \\
\hline 1993 & 2.713 \\
\hline 1994 & 2.660 \\
\hline 1995 & 3.135 \\
\hline 1996 & 3.700 \\
\hline 1997 & 3.671 \\
\hline 1998 & 4.575 \\
\hline 1999 & 5.147 \\
\hline 2000 & 4.943 \\
\hline & 5.709 \\
\hline
\end{tabular}

7 SUPERINTENDÊNCIA DA ZONA FRANCA DE MANAUS. Indicadores de desempenho do Pólo Industrial de Manaus: história do PIM em tabelas e tráficos, 1988 a 2006, p. 33. 


\begin{tabular}{|r|r|}
\hline 2001 & 6.566 \\
\hline 2002 & 7.490 \\
\hline 2003 & 9.052 \\
\hline 2004 & 10.264 \\
\hline 2005 & 11.303 \\
\hline 2006 & 12.831 \\
\hline
\end{tabular}

Quadro 4: Evolução da mão de obra do subsetor duas rodas (de 1990 a 2006). FONTE: SAP/CGPRO/COISE ${ }^{8}$.

A Moto Honda da Amazônia é um dos empreendimentos beneficiados pelo projeto da Zona Franca de Manaus, apresentado pelo então deputado federal Francisco Pereira da Silva. A ZFM foi criada pela Lei n. ${ }^{\circ} 3.173$, de 6 de junho de 1957, (BOTELHO, 2006), revogada pelo Decreto-Lei n. ${ }^{\circ} 288$, de 28 de fevereiro de 1967, que criou a Superintendência da Zona Franca de Manaus (BOTELHO, 2006).

A primeira planta da empresa foi instalada na cidade de Manaus em 1976, com a denominação Moto Honda do Brasil. Sua atividade consiste na produção e na venda de motocicletas e de produtos de força. A implantação da Moto Honda da Amazônia sustentou-se em benefícios resultantes da isenção de impostos concedida pelo Decreto-Lei n. ${ }^{\circ}$ 288, de 28 de fevereiro de 1967, que efetivou a Zona Franca de Manaus (BOTELHO, 2006).

\begin{tabular}{|l|}
\hline 1. DENSO \\
\hline 2. MASA DA AMAZÔNIA \\
\hline 3. IFER \\
\hline 4. NISSIN \\
\hline 5. SHOWA DO BRASIL \\
\hline 6. SCORPIOS \\
\hline 7. NIPPON DO BRASIL \\
\hline 8. MTSUBA \\
\hline 9. COSMOSPLAST \\
\hline 10. BRASSINTER \\
\hline 11. MUSASHI \\
\hline 12. FCC DO BRASIL \\
\hline 13. METAL FINO \\
\hline
\end{tabular}

8 SUPERINTENDÊNCIA DA ZONA FRANCA DE MANAUS. Indicadores de desempenho do Pólo Industrial de Manaus: história do PIM em tabelas e tráficos, 1988 a 2006, p. 98. 


\begin{tabular}{|l|}
\hline 14. SODEX DA AMAZONIA \\
\hline 15. ITALO LANFRED S.A., FEDERAL MOGOS \\
\hline 16. EXAVALENTE \\
\hline 17. ZEMAC \\
\hline 18. TECAL \\
\hline 19. DEIROL \\
\hline
\end{tabular}

Quadro 5: Fornecedores da MHA.

FONTE: Elaboração de Eudes Melo.

A inovação tecnológica, o grande contingente de mão de obra barata (VALLE, 2007), a instalação de máquinas modernas, o fornecimento de insumos locais e a progressiva expansão de empresas fornecedoras locais - tudo isso somado ao modelo da produção flexível, já aplicado desde 1976, data da instalação da MHA no Polo Industrial de Manaus - têm sido fundamentais para o aumento da produtividade dessa organização. A velocidade produtora impressiona quem visita a fábrica. Em uma visita que fizemos à MHA em abril deste ano, o apresentador informou-nos que, em uma das três linhas de montagem, a produção de uma motocicleta simples era concluída a cada 32 segundos e, em outra linha, os operários encerravam uma moto das mais sofisticadas a cada 38 segundos. A MHA tem ampliado suas exportações para o mercado externo. Em 2004, essa exportação representava 5\% (ALVES, 2004). Segundo dados de setembro de 2008, a MHA alcançou o percentual de $9 \%$ de vendas dos seus produtos para o exterior (SINDI/ FIEAM/CNI, 2008).

De acordo com os dados da pesquisa do Observatório Social, a Moto Honda da Amazônia abrange 3.600 colaboradores, dos quais $26 \%$ são de pessoal indireto. A Honda (HAD) possui 2.782 colaboradores, $6 \%$ do sexo feminino. A Honda Componentes da Amazônia (HCA) possui 75 colaboradores, com idade média de 30 anos. A HTA possui 61 colaboradores, 74\% formados de pessoal direto (OBSERVATÓRIO SOCIAL, 2001, p. 42).

Certamente esses dados carecem de atualização, pois no momento ainda não se encontram disponíveis nos órgãos que consultamos: Sindicato dos Metalúrgicos de Manaus, Federação das Indústrias do Estado do Amazonas (FIEAM) e Instituto Brasileiro de Geografia e Estatística (IBGE). Na FIEAM, argumentaram que, caso nos fornecessem os dados, estariam quebrando o acordo de sigilo ético da informação, firmado com a MHA. Essa foi também a resposta dada pelo IBGE. 


\section{CONSIDERAÇÕES FINAIS}

A nova configuração do cenário mundial caracteriza-se pela instabilidade permanente da economia mundial, em função da mundialização do capital, da desregulamentação de direitos e da flexibilização da produção decorrente da reestruturação produtiva nas grandes corporações. É nesse quadro que se insere a Zona Franca de Manaus. Na Zona Franca de Manaus, o trabalho e as concessões fiscais são decisivos. A relação entre o local e o global é ao mesmo tempo de oposição e de complementação.

A relação entre as empresas fornecedoras e a Moto Honda da Amazônia ganha relevância não somente pelo peso da MHA no Polo Industrial de Manaus (PIM) e sua hegemonia no subsetor do Polo de Duas Rodas (PDR), mas também pelos fatores sociais implicados diretamente nessa relação. Há um crescimento da contratação de mão de obra tanto pela MHA, quanto pelas suas fornecedoras, o que representa um impacto social indireto.

As estratégias de formação de redes produtivas, o método japonês de organização da produção, o processo de inovação tecnológica, a concentração de uma significativa quantidade de força de trabalho são fatores que têm reordenado e reconfigurado o universo da produção na Moto Honda da Amazônia e no Polo Industrial de Manaus. Alia-se a isso o marco que representou a Lei n. ${ }^{\circ}$ 8.387, que estabelece o índice mínimo de nacionalização de componentes das etapas básicas de produção, isto é, o estabelecimento de um novo regime produtivo, consequentemente o aumento da utilização da capacidade instalada, com o uso de máquinas. Esses fatores são ilustrativos de uma indústria que se distancia daquela de há duas décadas, com alta capacidade de empregabilidade, produção e faturamento.

\section{REFERÊNCIAS}

ALVES, Marcelo Magaldi. Os impactos da abertura econômica na Zona Franca de Manaus e o desempenho do setor externo dos pólos eletrônicos e de duas rodas no periodo de 1990 a 2004. 2005. Mimeografado.

ANTUNES, Ricardo. Os sentidos do trabalbo: ensaio sobre a afirmação e a negação do trabalho. 5. ed. São Paulo: Boitempo, 1999.

BAUMAN, Zygmunt. Globalização: as conseqüências humanas. Rio de Janeiro: Zahar, 1999.

BOTELHO, Antônio José. Redesenhando o projeto ZFM: um estado de alerta (uma década depois). Manaus: Valer, 2006. 
CASTELLS, Manuel. A era da informação: economia, sociedade e cultura. 9. ed. Rio de Janeiro: Paz e Terra, 2006, v. 1: A sociedade em rede.

COCCO, Giuseppe. Trabalho e cidadania: produção e direitos na era da globalização. 2. ed. São Paulo: Cortez, 2001.

DUPAS, Gilberto. Economia global e exclusão social: pobreza, emprego, Estado e o futuro do capitalismo. 3. ed. São Paulo: Paz e Terra, 2001.

HARVEY, David. Condição pós-moderna. São Paulo: Loyola, 1999.

HONDA bateu recorde de vendas de motos no país. 2004. Disponível em: <http://www2.uol.com.br/canalexecutivo/notasemp/emp070120052.htm>. Acesso em:

IANNI, Octávio. Teorias da globalização. 5. ed. Rio de Janeiro: Civilização Brasileira, 1999.

RAMALHO, José Ricardo. Novas conjunturas industriais e participação local em estratégias de desenvolvimento. In: RAMALHO, José Ricardo; SANTANA, Marco Aurélio (Org.). Trabalbo e desenvolvimento regional: efeitos sociais da indústria automobilística no Rio de Janeiro. Rio de Janeiro: Mauad X, 2006, v. 1. p. 11-42. SERÁFICO, José; SERÁFICO, Marcelo. A Zona Franca de Manaus e o capitalismo no Brasil. Estudos Avançados, v. 19, n. 54, São Paulo, p. 99-113, maio/ago. 2005.

SILVA, Marilene Correa da. Metamorfoses da Amazônia. Manaus: EDUA, 2000.

SUPERINTENDÊNCIA DA ZONA FRANCA DE MANAUS. Disponível em: <http://www.suframa.gov.br>. Acesso em: VALLE, Izabel. Globalização e reestruturação produtiva: um estudo sobre a produção offshore em Manaus. Manaus: EDUA, 2007. 